\title{
Final design research working title: creating a design idea for a customizable nursing bra for lactating 'millennimoms'
}

\section{Introduction}

This research will focus on creating a design idea for a prototype of a customizable nursing bra for lactating millennial mothers using Lamb and Kallal's FEA (Functional, Expressive, Aesthetics) Consumer Needs Model (1992). ${ }^{1}$ This research will also include inspiration from Park, Morris, Stannard and Hamilton, ${ }^{2}$ who explored 'universal design' within the textile and apparel field and displayed how it could be used as an effective framework for the apparel design process to achieve a variety of flexible and versatile outcomes by using some or all of 7 design principles (equitable use, flexibility in use, simple and intuitive in use, perceptible information, tolerance for error, low physical effort, and size and space for approach and use). Universal design is the design of products and environments to be usable by all people, to the greatest extent possible, without the need for adaption or specialized design. ${ }^{3}$ The aim of this customizable bra idea will be to take the approach of Morris, Park and Sarkar ${ }^{4}$ to find the design requirements of a nursing bra for millennial moms, but also to combine several features that they deem necessary into one bra--making it customizable. Park et al. ${ }^{2}$ proved that the practice of universal design for apparel products will not always necessarily yield to resulting in 'design for all', but instead can yield to the 'design for many' motto; which means the apparel products will offer flexible fit and sizes to as many wearers as possible. They encouraged designers, students, and researchers to "explore their creativity and critical thinking skills in finding innovative design solutions for flexible and versatile apparel products". ${ }^{2}$

The target for this study will be between the ages 20-35. This target group is the economic, driving force behind many consumer products today and have been found to have a heavy influence amongst their peers and others, as they often are the ones to connect through social media to give advice and feedback to others on the products most used. ${ }^{5}$ The needs of nursing mothers will be identified through using social media and blog sites, as through a small sample of millennial mothers who are willing to participate.

What is missing in the millennial mother community is one nursing bra that can serve more than one purpose. Morris, Park, and Sarkar ${ }^{4}$ created a sports bra for breastfeeding mothers who wished to be physically active. Their purpose was to understand the design requirements of physically active breastfeeding moms for a sports bra design; however, there are no current "everyday" customizable nursing bras on the market. There are nursing bras that provide the ease of feeding, there are soothing pads for the nipples, nipple cream, and there are breast-pumps that help with the massaging and lactation of breasts, however, there is not a single nursing bra that can allow these options to be put into one product. "To the best of the authors' knowledge, there is no research effort in the current literature, to date, in developing a hybrid nursing/sports bra for breastfeeding women". ${ }^{4}$ This gives room for this study to address that need as closely as possible. Adding product personalization to new and repeat mothers will give them the sense of control and allow them is feel more comfortable wearing a bra that is customizable to their needs.

\author{
Volume 4 Issue 6 - 2018 \\ Sheiron Crawford \\ Graduate Research \& Teaching Assistant, University of Delaware, \\ USA
}

Correspondence: Sheiron Crawford, Graduate Research \& Teaching Assistant, University of Delaware M. S. Fashion and Apparel Studies 18', 306 Alison Hall, USA, Email screwfo@udel.edu

Received: May 30, 2018 | Published: November 29, 2018

Though all mothers are different in many ways, a lot of them experience the same things when it comes to nursing. Neifert, DeMarzo, Seacat, Young, Leff, and Orleans (1990) discovered that women who wish to engage in physical activity and who are also breastfeeding are at greater risk for breast pain and soreness due to increased breast volume and sensitivity associated with breastfeeding. ${ }^{6}$ Costantakos \& Watkins ${ }^{7}$ reported that the volume changes of breasts are in response to changing hormonal concentrations during pregnancy and nursing can cause them to become very sensitive and cause pain. Because the breasts do not have any muscles in them and are only supported by skin and thin ligaments, lactating breasts need additional support to sustain extra breast weight due to lactation. ${ }^{4}$ Bowles, Steele, Wu, Zhou, Spinks, Innis, and Wallace (2000) discovered that shoulder straps (width and the placement of them) are also key factors in the support of the breasts in sports bras. Though this study will focus on creating an everyday nursing bra, this information about sports bras is important to consider. ${ }^{8}$ What previous literature reveals is that lactating, nursing mothers endure change of volume in breasts, which can also cause pain. With this in mind, a customizable nursing bra that can be used for everyday use must provide enough support and give enough comfort to lessen as much pain as possible. This study proposes to create a design idea that will ease the pain of lactating breasts as well as have customizable features that gives ease of use for breastfeeding mothers. The ultimate goal is to mass produce a customizable bra that can accommodate many mothers.

Park et al. ${ }^{2}$ study briefly touched on product personalization as an alternative to universal design for those "individualistic" consumers. However, they also acknowledged that the goal of universal design is to "offer flexible, customizable options to as many end-users as possible". ${ }^{2}$ This study proposes that there is a way to combine universal design and product personalization in a way that does not force the concepts to counteract one another. With using a market such as breastfeeding millennial mothers, there can be a way for them to customize a nursing bra that can later be mass produced for others to try. NIKEiD allows consumers to design a shoe particularly for their individualistic wants/needs. ${ }^{9}$ However, if it is a popular design, it can be mass produced for as many consumers that want them. Millennial 
mothers often have similar nursing needs and they participate in the trend of asking other moms what techniques of parenting works best for them through networking. They eventually may adopt, change or reject those habits based on their individual preferences. This study aims to try a format such as NIKEiD, but for nursing bras to cater to the similar yet different needs of breastfeeding moms; whether it is to soothe the nipple, massage the breast to enhance lactation, provide ease of breastfeeding using a flap, or all of the above in one bra. The idea is to provide as many options as possible for as many as possible. ${ }^{10,11}$

\section{Acknowledgments}

None.

\section{Conflicts of interest}

Author declares there is no conflicts of interest in publishing the article.

\section{References}

1. Lamb JM, Kallal MJ. A conceptual framework for apparel design. Clothing \& Textiles Research J. 1992;10(2):42-47.

2. Park J, Morris K, Stannard, C, et al. Design for many, design for me: universal design for apparel products. The Design J. 2014;17(2):267290.
3. Mace R. Universal Design, Barrier Free Environments for Everyone Los Angeles, CA: Designers West; 1985.

4. Morris K, Park J, Sarkar A. Development of a nursing sports bra for physically active breastfeeding women through user-centered design. Clothing \& Textiles Research J. 2017;35(4):290-306.

5. Parnell B. Millennial moms: who they are \& what they care about steadfast creative. 2016.

6. Neifert M, DeMarzo S, Seacat J, et al. The influence of breast surgery, breast appearance, and pregnancy-induced breast changes on lactation sufficiency as measured by infant weight gain. Birth. 1990;17(1):31-38.

7. Bowles KA, Steele J, Wu J, et al. Breast bounce, brassiere straps and conducting polymers: a novel approach to assessing dynamic loading. Munich, Germany: Paper presented at the Scientific Millennium Meeting; 2000.

8. Costantakos AV, Watkins SM. Pressure analysis as a design research technique for increasing the comfort of nursing brassieres. Home Economics Research J. 1982;10(3):271-278.

9. Team T. How NIKEiD is helping Nike's push for greater profits. 2015.

10. McRoberts LB, Black CM, Cloud RM. Evaluation of a prototype soft-structured thoracic posture support garment. Clothing \& Textiles Research J. 2016;34(2):143-158.

11. Singh P, Gahlot M. Functional clothing for lactating women: a user oriented product development approach. IJAR. 2016;2(6):1028-1033. 